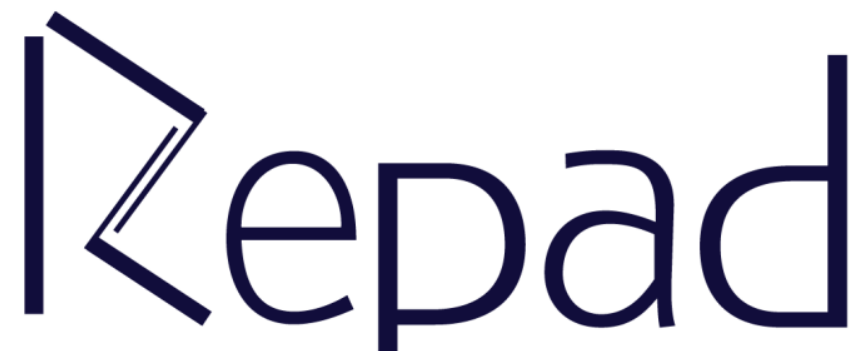

Vol. 1, N. 1 Dezembro/2017

Revista Estudos e

Pesquisas em Administração

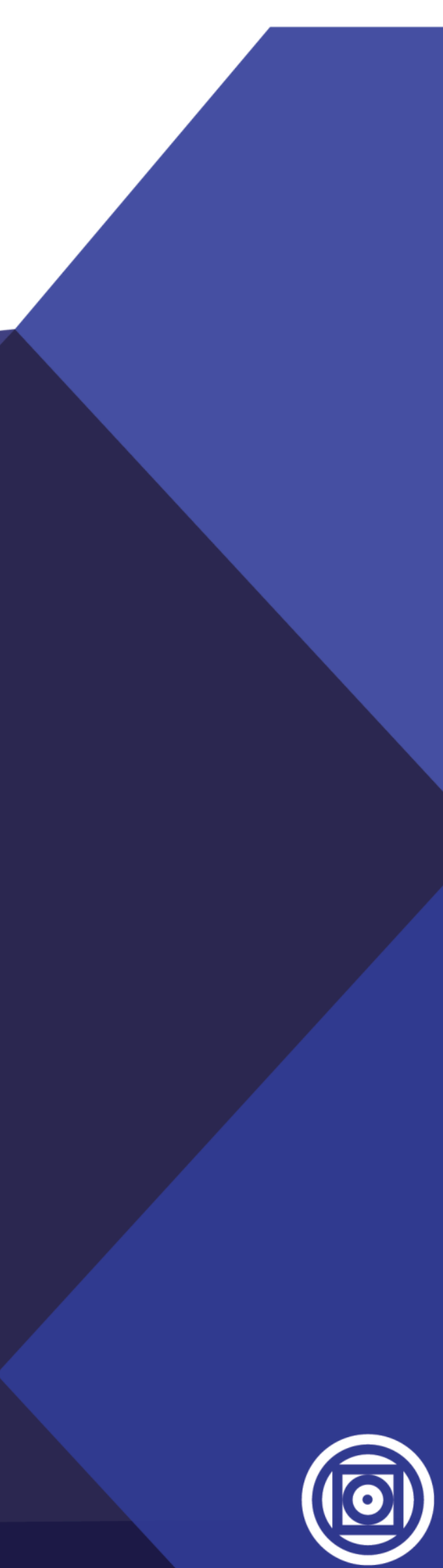




\title{
FERRAMENTAS COMO FATOR DE INOVAÇÃO NAS MICRO E PEQUENAS EMPRESAS
}

\author{
Idineia Bressan \\ Faculdade Católica de Mato Grosso - SEDAC - Campus Cuiabá \\ Ivana Aparecida Ferrer Silva \\ Universidade Federal de Mato Grosso \\ Simone Hirata \\ Universidade Federal de Mato Grosso \\ Willian Luan Rodrigues Pires \\ Universidade Federal de Mato Grosso \\ Elba de Oliveira Pantaleão \\ Universidade Federal de Mato Grosso
}

\section{RESUMO}

Desenvolver sustentavelmente tornou-se um desafio para as Micro e Pequenas Empresas (MPE), visto que as exigências são inúmeras quando se fala em impactos ambientais, dessa maneira, o principal objetivo desta pesquisa é descrever as práticas de inovações sustentáveis que uma microempresa do ramo de lavanderia realiza e identificar as ferramentas utilizadas por ela como estratégia para essas inovações. A pesquisa é teórica, na qual foram utilizadas técnicas bibliográfica e documental, os dados são extraídos de fontes secundárias. Para a análise e interpretação dos dados foi feito um estudo de caso da empresa pesquisada, cujos resultados demonstraram que a empresa é inovadora no quesito desenvolvimento sustentável, além de ser uma referência em sua área de atuação. Concluímos que as ferramentas que viabilizam a inovação sustentável na empresa estudada são: Ecoeficiência, Produção Mais Limpa e a Política de Gestão dos Resíduos Sólidos.

Palavras-chave: Micro e Pequenas Empresas; Estratégia; Inovação sustentável.

\section{TOOLS AS A FACTOR OF INNOVATION IN MICRO AND SMALL BUSINESSES}

\begin{abstract}
Developing in a sustainable way has become a challenge for micro and small enterprises (MPE), since the requirements are numerous when it comes to environmental impacts; thus, the main objective of this research is to describe the practices of sustainable innovations that a micro laundry business performs and identify the tools used as a strategy for these innovations. The research is theoretical, in which bibliographic and documentary techniques were used, the data were drawn from secondary sources. For the analysis and interpretation of the data a case study of the researched company was conducted, whose results showed that the company is innovative in terms of sustainable development, besides being a reference in its area of operation. We conclude that the tools that enable sustainable innovation in the company studied are: eco-efficiency, cleaner production and the solid waste management policy.
\end{abstract}

Keywords: Small Business; Strategy; Sustainable Innovation. 


\section{INTRODUÇÃO}

A responsabilidade socioambiental tornou-se um diferencial nas empresas contemporâneas que têm como desafio atual produzir e ofertar produtos e serviços de forma sustentável, abarcando a preocupação com o desempenho e o desenvolvimento de suas atividades e os seus impactos no ambiente. Como os recursos naturais precisam ser preservados por não serem ilimitados, existe em contraponto à necessidade de fomentar a economia e atender as demandas da sociedade. Surge nesse momento a necessidade de inovar sustentavelmente, um processo que requer uma visão holística do sistema organizacional de forma a atender a três demandas essenciais: econômica, social e ambiental.

No Brasil surgiu a Lei de $n^{\circ} 10.973 / 2004$ com o objetivo de incentivar a inovação através das Micro e Pequenas Empresas (MPE's), que em seu artigo 21 estabelece que "as agências de fomento deverão promover, por meio de programas específicos, ações de estímulo à inovação nas micro e pequenas empresas, inclusive mediante extensão tecnológica realizada pelas Instituições Científica e Tecnológica”. Apesar das questões burocráticas, acredita-se que o desenvolvimento de políticas de fomento à inovação seja importante para viabilização da efetividade das práticas inovadoras nas MPEs.

As empresas inovam para se adequar às legislações ambientais, cujas normas servem como resposta do poder público às denúncias crescentes da sociedade aos órgãos de proteção ao meio ambiente. Um exemplo é a Lei $\mathrm{n}^{\circ}$ 12.305/2010 que instituiu a Política Nacional de Resíduos Sólidos (PNRS), na qual se determina que as empresas insiram no processo de produção a logística reversa5, além de estabelecer a responsabilidade compartilhada entre a empresa, o consumidor e o poder público.

Dias (2013) afirma que existe no mínimo 3 motivos pelos quais as MPEs devem se preocupar em desenvolver práticas sustentáveis. $\mathrm{O}$ primeiro refere-se às cobranças de uma sociedade que está cada vez mais consciente e, em consequência, tende a exigir leis mais rígidas. O segundo está relacionado às exigências das grandes empresas, visto que estas preferem fornecedores e parceiros que adotem estratégias sustentáveis nos processos. O terceiro engloba questões de competitividade, pois compreende que o governo também tem responsabilidade social. Neste último caso, podemos citar como exemplo, uma licitação em que um dos critérios de escolha da empresa considere atitudes sustentáveis desenvolvidas pelos participantes do certame.

Diante da alta competitividade e do capitalismo empresarial, a inovação é um prérequisito para a inserção e manutenção das empresas, inclusive para as MPEs, diante da concorrência de mercado. Os consumidores estão mais exigentes e informados, procuram e preferem produtos ecológicos que possam ser reaproveitados, reutilizados e reciclados, exigindo que as organizações se posicionem diante dos problemas ambientais.

Dessa maneira, o objetivo dessa pesquisa é analisar as práticas que uma microempresa do ramo de lavanderia realiza, identificando as ferramentas utilizadas por ela como estratégia para Inovação Sustentável.

Nesse contexto, passamos a levantar a seguinte questão: quais as ferramentas que as micro e pequenas utilizam ao desenvolver a inovação sustentável? Observamos que a obrigatoriedade exige mudanças que em princípio são tidas como de alto custo, mas que em longo prazo, podem ser compensatórias através de benefícios como: reduções de custos fixos, minimização do desperdício de matéria-prima, além de melhoria da imagem institucional junto aos parceiros e ao público. 
Segundo SEBRAE (2014), existe no Brasil 8,9 milhões de micro e pequenas empresas que representam 27\% do Produto Interno Bruto (PIB) do país, um percentual relevante e que demonstra a importância das MPEs na economia brasileira como geradoras de emprego e renda.

Tendo em vista que as empresas de pequeno porte são consideradas como as principais geradoras de riqueza no comércio brasileiro, com 53,4\% do PIB (SEBRAE, 2014) neste setor, inovar é uma estratégia que resulta em vantagem competitiva para as organizações e quando aliada ao fator sustentabilidade, pois agrega valor à sua reputação diante do mercado consumidor e de sua concorrência, atendendo às expectativas e às necessidades demandadas pelos stakeholders.

Por isso, é imprescindível que as MPE’s tenham atitudes inovadoras que favoreçam a produção sustentável, ou seja, que atendam as necessidades presentes sem impactar gerações futuras. Justifica-se a relevância desse estudo pela importância do mapeamento prévio das ferramentas utilizadas no processo de inovação sustentável para esse perfil de empresa e assim minimizar a probabilidade de insucesso do empreendimento.

\section{REFERENCIAL TEÓRICO}

A revisão bibliográfica é composta pela fundamentação de inovação, no qual serão identificadas também algumas ferramentas utilizadas na Gestão Ambiental de uma Microempresa, com a Ecoeficiência, Produção Mais Limpa e a Política dos 3Rs.

\section{INOVAÇÃO}

Para Shumpeter (1982) inovar significa introduzir um novo produto, um método de produção, abrir um novo mercado, a conquista de uma nova fonte de matéria prima ou uma nova organização de qualquer indústria. Para Oslo (2005) a inovação não está apenas relacionada com a tecnologia, mas também com o aprimoramento das práticas produtivas, dos bens e de serviços disponibilizados no mercado, sendo vista como uma ferramenta de estratégia para a competitividade.

Muitos confundem as palavras Inovação e Invenção. A primeira remete a progressão, ao desenvolvimento por meio de um descobrimento quando colocado em prática (LABIM, 1995). A criação de um produto nem sempre será uma inovação. Para que seja considerado como tal "é preciso que o processo ou o produto seja rentável economicamente" (ZAWISLAK 1995, p. 148).

Silva (2012) afirma que as MPEs têm algumas vantagens na hora de inovar, pois são mais flexíveis quanto às mudanças, possuem profissionais multifuncionais e as decisões são centralizadas. Entretanto, percebe-se que é comum inovarem para corrigir algum erro, e não por exercitar a capacidade de inovar.

A mesma autora descreve quatro formas de conceito de inovação sustentável que se dividem em: a) Modelos Organizacionais: no qual política interna agrega princípios de gestão sustentável, sensibilização dos colaboradores e consultoria interna; b) Processos de Inovação Sustentáveis: no qual em suas práticas é desenvolvido algum processo inovador e ou sustentável em relação aos produtos, aos equipamentos e processos; c) Produtos inovadores e sustentáveis: registro de patentes, criação de produtos com ciclo de vida fechado e d) Pesquisa e Desenvolvimento: pesquisa e desenvolvimento de novos produtos e processos (SILVA, 2012).

Dessa maneira Silva (2012) destaca que a inovação sustentável não se limita a uma única maneira de adoção. A sustentabilidade é vista como a melhor das inovações deste século, pelo 
motivo de proporcionar o equilíbrio com a natureza por meio de padrões produtivos sustentáveis.

Para Tidd, Bessant e Pavitt (2005) as inovações ocorrem quando o processo organizacional é integrado à estratégia da empresa, resultando em vantagem competitiva. Os autores descrevem o processo de inovação em quatro etapas: analisar o ambiente interno e externo para poder identificar ameaças e oportunidades relacionados à mudança; decidir estrategicamente como desenvolver a mudança e quais demandas atender; obter recursos necessários para responder, por meio de serviço ou produto novo, pesquisa e desenvolvimento ou pela transferência de tecnologia. A última etapa refere-se à implementação do projeto, no qual irá desenvolver a tecnologia e o mercado irá atender.

Contudo, para a promoção da inovação, é preciso a articulação de três agentes principais, que segundo Silva (2012) são: o Estado, que fomenta políticas públicas; as universidades e institutos de pesquisa, que compartilham conhecimentos e as empresas, que investem na transformação dos produtos e serviços, viabilizando o desenvolvimento do país.

O governo com objetivo de incentivar a inovação no país, no ano de 2004 criou a Lei $n^{\circ} 10.973$ na qual estabelece medidas que viabilizam a pesquisa científica e tecnológica no ambiente produtivo. No artigo $2^{\circ}$, inciso IV, da referida Lei, encontramos o conceito de inovação como "introdução de novidade ou aperfeiçoamento no ambiente produtivo ou social que resulte em novos produtos, processos ou serviços". Surgem então as agências de fomento, compreendidas em Instituições Científica e Tecnológica (ICT) e os Núcleos de Inovação Tecnológica (NITs) entre outras. Essas agências de fomento devem promover, por meios de programas específicos, estímulo à inovação nas MPEs.

Apesar da existência de instituições públicas que promovem a inovação nas empresas de Mato Grosso, tal como a Secretaria de Estado de Ciência e tecnologia (SECITEC) e o Escritório de Inovação e Tecnologia (EIT) da UFMT, grande parte das empresas do Estado desconhece este suporte ou não participam dos editais por motivo de capacidade técnica ou por não ter confiança nos programas de inovação promovidos pelo governo (SILVA, 2012).

Para Barbieri (2007) não basta apenas que as empresas inovem, é necessário que elas se desenvolvam sustentavelmente considerando três dimensões: (1) Social, em que a empresa deve assumir responsabilidade social, pois as suas ações causam impactos internos e externos e por isso deve prestar suporte à comunidade, desenvolver os recursos humanos, além de promover e participar de projetos sociais; (2) Ambiental, que se refere ao atendimento das legislações, produção de produtos ecologicamente corretos, tecnologias limpas, reciclagem e tratamento de efluentes e resíduos, cujas práticas demonstrem a preocupação com o meio ambiente; e (3) Econômica, que está relacionada à obtenção de lucro e vantagem competitiva no mercado. Assim, para que o negócio seja sustentável deve ser em suma: ecologicamente correto, economicamente viável, socialmente justo e culturalmente aceito (SACHS, 2004). Atender essas dimensões torna o processo de inovação mais valorizado, visto que permite obter resultados positivos não apenas para a população, mas também para a organização.

Nesse contexto, o desenvolvimento sustentável deve ser visto não separadamente do desenvolvimento econômico, mas como um grande modelo de gestão que traz a vantagem competitiva de ser ecologicamente melhor (DONAIRE, 1999).

Barbieri (2004, p.20) afirma que esses valores "auxiliam para dotar a organização de vantagens competitivas sustentáveis, já que a empresa se antecipa no atendimento de novas demandas por meio de ações legítimas e verdadeiras, criando um importante diferencial estratégico". Empresas menores encontram maior dificuldade para obter financiamento do que as grandes que já possuem destaque para produção de tecnologia e produtos inovadores. 


\section{PRÁTICAS E FERRAMENTAS PARA O DESENVOLVIMENTO SUSTENTÁVEL ECOEFICIÊNCIA E PRODUÇÃO MAIS LIMPA}

A ecoeficiência é uma estratégia ambiental, pois refere-se à utilização dos recursos disponíveis no planeta com a máxima eficiência, e tem como princípio basilar a redução do consumo de energia e de matéria prima (BARBIERI, 2007).

Essa ferramenta agrega valor aos processos produtivos, pois otimiza o uso dos recursos, além de minimizar os resíduos provenientes da produção, posto que seus objetivos são: reduzir o consumo de água, energia e materiais não renováveis com bens e serviços; viabilizar a reciclagem e o aproveitamento dos materiais, aumentar o consumo de recursos renováveis, diminuir as substancias tóxicas; fomentar a competitividade entre as empresas e minimizar os impactos ambientais (DIAS, 2006).

O World Business Council for Sustainable Development (WBCSD, 2000) entende que a ecoeficiência é uma filosofia de gestão que possibilita ao empresariado procurar melhorias ambientais que resultem em benefícios econômicos. Concentra-se em oportunidades de negócio que permitem às empresas serem mais lucrativas e mais responsáveis ambientalmente, de modo a incentivar a inovação e, em consequência, o crescimento e a competitividade. No entendimento de Salgado (2007 apud ALVES et al., 2009) a ecoeficiência é uma das ferramentas que viabiliza a sustentabilidade empresarial, e surge como uma resposta das empresas para a as cobranças diárias de ações que integrem o desenvolvimento sustentável.

Para a efetivação da ecoeficiência, torna-se comum a adoção da Produção Mais Limpa $(\mathrm{P}+\mathrm{L})$ prática que se refere a realização contínua de estratégia econômica, ambiental e tecnológica voltada para a prevenção da poluição nos processos e produtos. A $\mathrm{P}+\mathrm{L}$ engloba qualidade, planejamento, segurança, meio ambiente, design, saúde ocupacional e eficiência do sistema produtivo (ELIAS et al., 2004).

Nascimento (2012) infere que práticas ecoeficientes geram melhorias econômicas, pois estas além de respeitar o meio ambiente, minimizam os custos mantendo a qualidade dos produtos e serviços prestados. $\mathrm{O}$ autor enfatiza que isso gera vantagem competitiva e potencializa os mercados já existentes.

Dessa forma, Kraetz e Alencastro (2013) enfatizam que P+Lé o uso ininterrupto de uma estratégia ambiental preventiva e se refere aos processos produtivos (conservação de matérias primas e energia, eliminação de matérias primas tóxicas, redução da quantidade e da toxidade dos resíduos e emissões gases poluentes), produtos (redução dos impactos negativos ao longo do ciclo de vida de um produto, desde a extração da matéria prima até sua disposição final) e serviços (incorporação de preocupações ambientais no planejamento de entrega dos serviços) para aumentar a ecoeficiência e reduzir os riscos na saúde humana e no meio ambiente.

Para Almeida (2002) a empresa aprende a valorizar os resíduos antes do descarte, ou seja, os rejeitos passam a ser colocados no mercado com valor e serviços agregados. Isso estimula a criatividade, direciona para a inovação e, portanto, a novos produtos.

Nesse sentido, existem no processo de produção três elementos exigidos pela $\mathrm{P}+\mathrm{L}$ : a melhoria tecnológica, aplicação de know how e a mudança de atitudes, o que se torna um diferencial quando comparada com outras técnicas produtivas (NASCIMENTO, 2012).

De acordo com o Conselho Empresarial Brasileiro para o Desenvolvimento Sustentável (CEBDS, 2015), a P+L pode ser utilizada como ferramenta para melhoraria de gestão ambiental da empresa no qual atinge:

- O ambiente interno: os gestores e colaboradores da organização

- As autoridades ambientais: por meio da adequação as exigências legais e ambientais.

- Os parceiros que interagem com a organização: terceirizados, fornecedores e distribuidores. 
- A comunidade em geral: por perceber as práticas de prevenção a poluição, na qual minimiza os danos para a população.

Para orientar as empresas com interesse na implantação da $\mathrm{P}+\mathrm{L}$, foi criada no Brasil uma rede denominada Rede de Produção Mais Limpa6, que tem como finalidade incentivar as práticas sustentáveis que viabilizam a inovação e a vantagem competitiva nas empresas. Essa rede produziu o "Guia da Produção Mais Limpa: faça você mesmo”, onde possui metodologias para implantação da $\mathrm{P}+\mathrm{L}$.

\section{POLÍTICA 3 RS DOS RESÍDUOS SÓLIDOS}

A Política dos 3 Rs refere-se a um princípio voltado para a gestão dos resíduos sólidos, no qual foi sugerido na Conferência da Terra realizada em 1992, com o intuito de diminuir o consumo desmedido pela população. Na agenda global, dois dos objetivos destacados no $21^{\circ}$ capitulo são a redução ao mínimo dos resíduos e a maximização ambientalmente saudável do reaproveitamento e da reciclagem dos resíduos. Um ano depois, em 1993 foi lembrado no $5^{\circ}$ Programa Europeu para o Meio Ambiente e Desenvolvimento.

Mousinho (1999, apud TRIGUEIRO, 2005) afirma que esse princípio tem como base uma hierarquia de procedimentos, a saber: Reduzir (matérias-primas e energia, a quantidade de material a ser descartado), este primeiro está ligado com o consumo consciente, reduzir o desperdício; Reutilizar (os produtos usados, dando a eles outros usos) encontrar funções secundárias para o produto que já realizou a sua função primária e que iria para o lixo; e Reciclar (retornar o que foi utilizado ao ciclo de produção) e produzir um material a partir de um produto já utilizado.

Ainda segundo a autora, "o princípio dos 3 Rs está orientado para uma mudança dos padrões não-sustentáveis de produção e consumo, não devendo, portanto, a reciclagem ser uma ação desvinculada dos dois primeiros Rs, o que poderia servir para legitimar o desperdício" (MOUSINHO, 1999 apud TRIGUEIRO, 2005, p.73).

No Brasil, no art. $3^{\circ}$ da Lei $n^{\circ} 12305 / 2010$, que instituiu a Política Nacional de Resíduos Sólidos, define a reciclagem como um "processo de transformação dos resíduos sólidos que envolve a alteração de suas propriedades físicas, físico-químicas ou biológicas, com vistas à transformação em insumos ou novos produtos" e a reutilização como "o processo de aproveitamento dos resíduos sólidos sem sua transformação biológica, física ou físicoquímica." Essas ferramentas podem ser aplicadas concomitantemente pelas empresas interessadas que estejam interessadas em resultados mais sólidos e que possam abranger todos os níveis de operação do negócio.

\section{PROCEDIMENTOS METODOLÓGICOS}

Trata-se de uma pesquisa exploratória e descritiva, na qual inicialmente foi realizado um levantamento bibliográfico, baseado em artigos, tese de doutorado e livros. Vergara (1998) afirma que pesquisa bibliográfica é o estudo sistematizado desenvolvido com base em material publicado em livros, revistas, jornais, redes eletrônicas, isto é, material acessível ao público em geral.

Realizou-se um estudo de caso em uma microempresa do ramo de serviços de lavanderia localizada no estado de Mato Grosso. Segundo Yin (2001), um estudo de caso é uma pesquisa empírica que investiga um fenômeno atual dentro de um contexto real e tem como diferentes fontes e evidencia. Vergara (1998) entende como um circunscrito de um ou múltiplos casos, de uma pessoa, família, um produto, uma empresa, um órgão público, uma comunidade ou um 
país, a autora salienta que esse tipo de estudo tem como característica profundidade e detalhamento. A principal característica de todos os estudos de caso é que estes tentam entender e esclarecer o motivo de determinada decisão ou um conjunto de decisões, como elas foram implementadas e quais os resultados conquistados (YIN, 2001).

Para coletar os dados da empresa foi realizada uma pesquisa documental, que para Zanella (2009) refere-se à análise de documentos internos como os relatórios e manuais da organização, notas fiscais entre outros ou externos da organização como as publicações (censo demográfico, industrial) e dados de pesquisa já aplicadas. Os autores Lakatos e Marconi (2001) inferem que a pesquisa documental é composta por dados de fontes primárias que pertence a arquivos públicos ou particulares de empresas ou pessoas, podendo conter também dados estatísticos, sendo estes documentos escritos ou não.

Gil (1999) afirma que esse tipo de pesquisa depende de materiais que ainda não foram analisados, e por isso podem ser reelaboradas conforme o objeto de estudo do pesquisador.

Dessa forma utilizou-se no estudo um projeto de sustentabilidade (documento interno) disponível no site da organização estudada e relatórios do Serviço Brasileiro de Apoio às Micro e Pequenas Empresas (SEBRAE, 2014).

\section{RESULTADOS E DISCUSSÕES}

\section{A Empresa}

A empresa "P" existe no mercado desde o ano de 2002 e atua no ramo de serviços de lavanderia e tinturaria, sendo composta de uma matriz e uma filial na cidade de Rondonópolis/MT e uma filial em Cuiabá/MT. O trabalho da empresa é tido como diferenciado pelo fato de ser uma empresa inovadora por empregar em sua rotina de trabalho conceitos de Desenvolvimento Sustentável até então não aplicados em empresas da região.

Em 2005, o proprietário passou a fomentar a ideia de inovar e oferecer serviços de lavagem, tinturaria e pequenos ajustes de roupas mais adequados à sua pretensão de negócio, visto que o mercado de lavanderia da região era composto basicamente por lavanderias informais. Nesse viés, passou a pesquisar e promover a necessidade de mudar a gestão e os processos da empresa, buscando incorporar a sustentabilidade ao seu ideal de negócio, seguindo a premissa de que queria ser mais produtivo, fazer menor uso de água e energia elétrica para que fosse oferecido menor preço aos consumidores.

Dentre os quatro conceitos de inovação sustentável citado por Silva (2012), a empresa se enquadra no Modelo organizacional e Processos de Inovação Sustentáveis, pois a organização agrega em sua política princípios de gestão sustentável, isso porque realiza um trabalho de sensibilização e treinamento com os colaboradores além de inserir no processo uma gestão inovadora que visa minimizar os impactos no meio ambiente, com auxílio de tecnologia e equipamentos sofisticados.

Sabendo que no processo de lavagem são gastos elevada quantidade de água e de produtos químicos (que causam sérios danos ambientais), gerando também gastos de energia, o dono da empresa compreendeu que era necessário a busca pela inovação e sustentabilidade ambiental, pois a gestão ambiental potencializa vários fatores que Dias (2006) identifica como itens medidores de competitividade e são eles: custo, qualidade do produto e serviços.

Donaire (1999) afirma que há benefícios econômicos que são a diminuição dos custos e de matéria prima, o incremento de receitas no qual se refere ao aumento da demanda e linha de novos produtos; além de benefícios estratégicos, que agregam valor aos recursos de reputação, 
aumentam a produtividade, estimulam a criatividade para novos desafios, além de melhorar a imagem corporativa diante stakeholders.

Em seu Projeto de Sustentabilidade, a empresa expressa que seu cuidado com o meio ambiente é divido em: a) ações operacionais, que compreendem as atividades operacionais e utilizam a tecnologia, a padronização e a automação dos processos para diminuir os impactos ambientais e b) ações administrativas, que são as aquelas em que a gestão de recursos e processos são planejados e executados com finalidade de diminuir custos e uso de insumos.

Para que esse conceito de inovação sustentável fosse compreendido e incorporado ao negócio, foram realizadas parcerias com os fornecedores de insumos e maquinários, possibilitando que cada vez que uma nova máquina seja adquirida, seus funcionários possam ser treinados para operá-la com segurança, evitando desperdício de insumos.

Com finalidade de consolidar o plano, adquiriu maquinário importado, estabeleceu parcerias com empresas responsáveis pelo suporte e manutenção dos equipamentos de lavagem e secagem das roupas, passou a oferecer treinamento para os colaboradores, padronizando os processos e operações, dentre outras mudanças a seguir analisadas.

A etapa inicial do projeto se deu com a mudança de rotinas mais simples, tais como: o reuso de sacolas na entrega dos consertos rápidos, a utilização de plástico ecológico para embalagem de roupas lavadas e a implantação de varais para secagem nos casos de entrega superior a 24 horas.

A etapa posterior consistiu na importação de tecnologia da Espanha e Suécia (maquinários); controle de consumo por processos de automação dos insumos/recursos de lavagem (produtos químicos); adaptação dos equipamentos de passagem roupas.

No processo produtivo, houve redução de $32 \%$ no consumo de água e $42 \%$ de gastos com manutenção de máquinas, visto que as antigas eram de operação manual e já estavam obsoletas. Após a inovação com a implantação de equipamentos modernos e computadorizados, a lavagem das peças passou a ser totalmente programada e controlada com medidor e redutor de consumo de água, de energia elétrica e produtos químicos como: detergentes, amaciantes e alvejantes, sendo estes selecionados com a quantidade adequada de acordo com a lavagem e o tipo de tecido em um painel eletrônico disponível na máquina.

Cabe observar que a empresa optou pela troca de produtos químicos pelos biodegradáveis certificados pelo Ministério da Saúde por meio da Agência Nacional de Vigilância Sanitária (ANVISA), além de realizar a neutralização do PH da água antes do descarte na rede de esgoto.

Além de reduzir o uso da matéria-prima e fazer o uso consciente da água, a empresa preza pelo uso eficiente da energia com o uso de energia eólica através de 12 exaustores que servem tanto na secagem da roupa (denominado de "varal ecológico") quanto na diminuição da temperatura no ambiente. Tais práticas resultaram em $20 \%$ de economia no consumo de energia no início da implantação do projeto, além de não emitir gases poluentes e nem gerar resíduos. Isso é compatível ao que Barbieri (2007) postula sobre a ecoeficiência, principalmente quando diz que o uso dos recursos disponíveis deve ser feito com a máxima eficiência com o objetivo de mitigar o consumo de energia e de matéria-prima.

Para roupas com prazo de entrega de até 24 horas, são usadas secadoras que são movidas a gás liquefeito de petróleo (GLP), que possui alto poder calorífico e transforma a mesma quantidade de calor com menos quantidade de gás, reduzindo dessa maneira a emissão do carbono, um dos gases causadores do efeito estufa. O consumo em média de GLP por quinzena é de $185 \mathrm{~kg}$.

As peças com prazo de entrega superior a 48 horas são colocadas em varais para secar naturalmente, pois o clima quente da região centro-oeste favorece esse processo, reduzindo ainda mais o consumo de energia elétrica. 
As entregas das roupas são feitas com um triciclo ao invés de um carro de grande porte, por consumir menos combustível. Com essa troca foi gerada uma economia de $36 \%$ em combustível e consequentemente, emissão de menos gases poluentes no ar como: dióxido de carbono (CO2), monóxido de carbono $(\mathrm{CO})$, óxidos de nitrogênio (NOx), hidrocarbonetos não queimados (HC), e compostos de chumbo e dióxido de enxofre.

Dessa forma, é possível afirmar que existe a Produção Mais Limpa efetiva no processo de trabalho da empresa estudada. Kraetz e Alencastro (2013) diz que a P+L é uma estratégia ambiental preventiva, sendo assim visíveis nas atividades de produção da empresa, quando economiza água e energia, elimina matérias primas tóxica, quando utiliza produtos biodegradáveis e reduz a quantidade e a toxidade dos resíduos e emissões gases poluentes.

A ecoeficiência e a reutilização ( $3 \mathrm{R}^{\prime} \mathrm{s}$ ) estão presentes na redução do consumo de recursos naturais, pois as sacolas utilizadas na entrega da roupa são de papel ou plásticas, todas reaproveitadas ou reutilizadas, com exceção das embalagens dos edredons, colchas e cobertores, que necessitam de uma embaladora específica (alimentada com plástico ecológico). Essa atitude reduziu de 6 para 2 tipos de bobinas de sacolas plásticas, visto também que consequentemente, houve uma redução segundo o empresário de $32 \%$ na compra desse tipo de material, isto vem a conciliar com que o Nascimento (2012) diz que a ecoeficiência minimiza os custos e melhora a economia empresarial.

A combinação da automação com o uso adequado dos insumos químicos promoveu a uniformização dos processos e a diminuição dos custos, resultando em maior competitividade, conforme Figura 1.

Figura 1. Fatores resultantes incorporados ao negócio

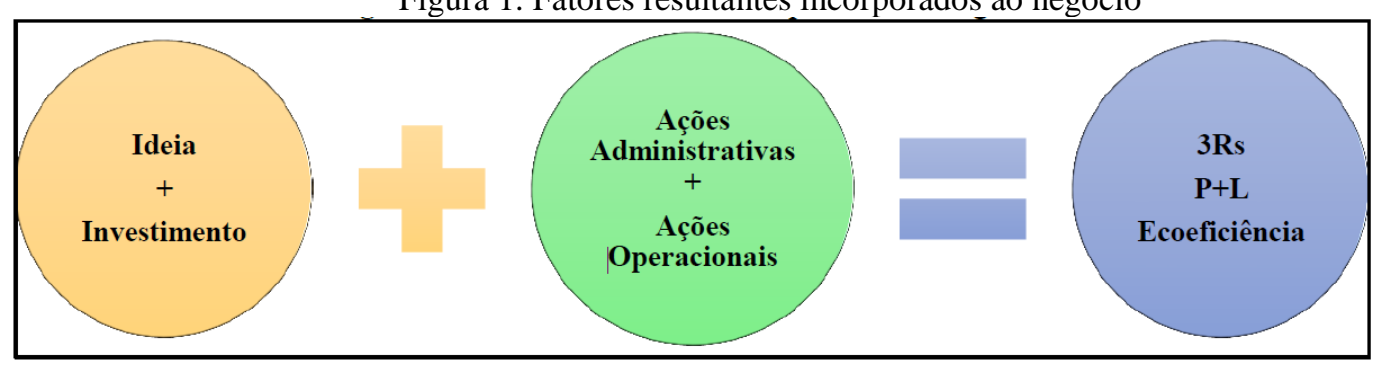

Fonte: Elaboração dos autores (2017)

O investimento total de $\mathrm{R} \$ 152.000,00$ foi recuperado em 02 anos e 7 meses, e o faturamento mensal da empresa passou a ser 5 vezes maior quando comparado ao período anterior às mudanças. Demais resultados são apresentados no Quadro 1.

Quadro 1- Resultados após implantação de processos de inovação sustentável

\begin{tabular}{|c|c|}
\hline Crescimento & Redução \\
\hline $8 \%$ na receita mensal & $2,8 \%$ no custo médio \\
\hline $89 \%$ de aumento médio na lucratividade & $32 \%$ no consumo de água \\
\hline $\begin{array}{l}0,6 \% \text { para } 1,07 \% \text { de elevação na } \\
\text { rentabilidade do negócio }\end{array}$ & $7 \%$ no consumo de energia elétrica \\
\hline \multirow[t]{3}{*}{$\begin{array}{c}\text { Faturamento de } \mathrm{R} \$ 12 \text { mil para } \mathrm{R} \$ 60 \mathrm{mil} \\
\text { mensais }\end{array}$} & $38 \%$ no consumo de plástico \\
\hline & $36 \%$ no consumo de combustível \\
\hline & $42 \%$ de custo de manutenção de equipamentos \\
\hline
\end{tabular}

Fonte: Sebrae (2012-2014), adaptado. 


\section{CONSIDERAÇÕES FINAIS}

A empresa "P" ao incorporar à sua visão empresarial os processos administrativos e operacionais aos conceitos de desenvolvimento sustentável, passou a promover a inovação sustentável em seu negócio, fator primordial para diferenciação no mercado e vantagem competitiva.

Com o uso de insumos biodegradáveis, fontes de energia alternativa (GLP, luz solar, eólica), reutilização de embalagem, automação de processos dentre outros recursos, a empresa acabou por executar várias ferramentas de gestão ambiental sustentável, das quais destacamos os 3Rs, a ecoeficiência e a P+L e não necessariamente um Sistema de Gestão Ambiental (SGA), mas pequenas atitudes com o uso dessas ferramentas geram resultados satisfatórios para a população, e as microempresas podem continuar competitivas respeitando o meio ambiente.

Diante dos resultados, concluímos que existem micros e pequenas empresas no Estado de Mato Grosso com atitudes inovadoras e sustentáveis, pois são diversas as barreiras identificadas, sendo a mais específica para esse porte de organização a dificuldade de acesso ao crédito para investimentos. Por isso, é preciso mitigar as lacunas existentes entre as MPEs e as instituições de fomento para que o desenvolvimento da inovação sustentável seja inserido nessas organizações.

Apesar ter grande representatividade no Brasil, as MPEs geralmente têm uma estrutura mais frágil quanto à qualificação de pessoal e tecnologia inserida no sistema organizacional, o que inviabiliza a inovação, isso porque a maioria inova por necessidade, ou seja, de forma mais passiva, enquanto as grandes organizações são mais ativas.

Por isso, é relevante ressaltar que para implantação desse sistema de controle de lavagem, foi necessário o gestor investir em equipamentos de alto padrão tecnológico, o que para uma micro e pequena empresa pode ser uma barreira pela falta de capital, e como Barbieri (2004) afirma, as empresas menores têm maior dificuldade para conseguir financiamento. Apesar da Lei de Inovação determinar incentivos a esse porte de empresa, segundo Silva (2012), a maioria das empresas de Mato Grosso desconhece este suporte ou ficam excluídas de editais por não conformidade, enquanto outras não se sentem seguras com os programas de inovação proposto pelo governo.

O compromisso dos gestores em compartilhar e agregar valores ambientais ao seu negócio, bem como a atualização e treinamento de empregados e parceiros fundamentados nesse mesmo ideal possibilitou resultados positivos, inclusive da expansão da empresa como franquia para outras cidades, posteriormente onde o modelo de gestão considerado de sucesso foi replicado.

Fica explicito que as MPEs têm capacidade para a inovação sustentável e pode ser um diferencial no seu mercado de atuação. Contudo, é oportuno salientar que para isso é preciso que busquem parcerias com outras empresas, comunidade, governo, stakeholders e se adequem a uma ferramenta de gestão ambiental, incluindo então a responsabilidade compartilhada no processo e a incorporação desses fundamentos em todos os níveis de gestão e operação do negócio.

\section{REFERÊNCIAS}

ALMEIDA, F. O bom negócio da sustentabilidade. 1. ed. Rio de Janeiro: Nova Fronteira, 2002. 
BARBIERI, J. C. Gestão ambiental empresarial. São Paulo: Saraiva, 2004.

Desenvolvimento e meio ambiente: as estratégias de mudança da agenda 21. 8 . ed. Petrópolis, RJ: Vozes, 2007

BRASIL. Lei de Inovação Tecnológica (Lei n. ${ }^{\circ}$ 10.973/2004). Brasília, DF: Congresso Nacional. Atos do Poder Legislativo, DOU, n. 232 de 03.12.2004.

CEBDS. Conselho Empresarial Brasileiro para o Desenvolvimento Sustentável.

Disponível em: <http://www.cebds.org.br/>. Acesso em: 01 de setembro de 2015.

DONAIRE, D. Gestão Ambiental na Empresa 2.ed. São Paulo: Atlas, 1999

DIAS, R. Gestão Ambiental: responsabilidade social e sustentabilidade. São Paulo: Atlas, 2006.

Sustentabilidade como condição para que uma empresa permaneça no mercado. In: Produção e Consumo Sustentáveis: Oportunidade e diferencial competitivo a partir do empreendedorismo sustentável, Brasília: SEBRAE, 95. pp, 2013. Disponível em: $<$ http://www.sebrae.com.br/customizado/acesso-a-mercados/conheca-seu-mercado/mercadose- sustentabilidade/producao_e_consumo_sustentaveis.pdf $>$. Acesso em 01 de setembro de 2015.

ELIAS, S.J.B.; PRATA, A. B.; MAGALHÃES, L.C. Experiência de implantação da Produção Mais Limpa: Estudo de Múltiplos Casos. Florianópolis: XXIV Encontro Nacional de Engenharia de Produção (ENEGEP), 2004.

GIL, A. C. Métodos e técnicas de pesquisa social. 5.ed. São Paulo: Atlas, 1999.

- Inovação e Sustentabilidade: Bases para o Futuro dos Pequenos Negócios. Seminário Internacional sobre Pequenos Negócios. São Paulo: SP, Brasil, 2012.

KRAETZ, G; ALENCASTRO, M. S. C. Sistema de Gestão Ambiental, Produção mais Limpa e Ecodesign: diferencial competitivo e inovador para as empresas brasileiras. Revista das Faculdades Santa Cruz, v. 9, n.1, 2013.

LABIM, J. J. Marketing Estratégico. 3. Ed. Madrid: Mc Graw Hill, 1995.

LAKATOS, E. M.; MARCONI, M. A. Fundamentos metodologia científica. 4.ed. São Paulo: Atlas, 2001.

MINISTÉRIO DO MEIO AMBIENTE. Agenda 21 Global. Disponível em http://www.mma.gov.br/responsabilidade-socioambiental/agenda-21/agenda-21-global.

Acessado em 01 de setembro de 2015.

MOUSINHO, P. Dicionário Brasileiro de Ciências Ambientais. Rio de Janeiro: Thex Editora, 1999. In: TRIGUEIRO, A. Mundo sustentável: abrindo espaço na mídia para um planeta em transformação. São Paulo: Globo, 2005 
NASCIMENTO, L. P. Gestão Ambiental e Sustentabilidade - Florianópolis: Departamento de Ciências da Administração /UFSC; [Brasília]: CAPES: UAB, 2012. 148p.

PROGRAMA NACIONAL DE RESÍDUOS SÓLIDOS. Lei 12.305 e 7.404. Disponível em: <http://www.mma.gov.br/port/conama/legiabre.cfm?codlegi=636>. Acesso em 10 de agosto de 2015.

REDE DE PRODUÇÃO MAIS LIMPA. Guia de Produção Mais Limpa: faça você mesmo. Disponível em http://www.gerenciamento.ufba.br/Downloads/guia-da-pmaisl.pdf . Acesso em 05 de Maio de 2015.

SACHS, I. Desenvolvimento: includente, sustentável, sustentado. Rio de Janeiro: Garamond, 2004.

SALGADO, V. G. Indicadores de Ecoeficiência e o Transporte de Gás Natural. In: ALVES, J. L. S.; MARTINS, H.S.A.; MEDEIROS, D. D. Ecoeficiência como fator de inovação nas micro e pequenas empresas: um estudo de caso. In: XXIX Encontro Nacional de Engenharia de Produção - ENEGEP, 2009, Salvador. XXIX ENEGEP, 2009.

SEBRAE - Serviço Brasileiro de Apoio às Micro e Pequenas Empresas - Participação das Micro e Pequenas empresas na Economia Brasileiras - 2014 Disponível em http://www.sebrae.com.br/Sebrae/Portal\%20Sebrae/Estudos\%20e\%20Pesquisas/Participacao $\% 20$ das\%20micro\%20e\%20pequenas\%20empresas.pdf. Acesso dia 11 de abril de 2015.

SILVA, I. A. F. Inovação Sustentável do Estado de Mato Groso: setores de alimentos e madeireiro-1970-2012. Tese (Doutorado) - Universidade Federal do Pará, Núcleo de Altos Estudos Amazônicos, Programa de Pós-Graduação em Desenvolvimento Sustentável do Trópico Úmido, Belém, 2012.

TIDD, J.; BESSANT, J.; PAVITT, K. Managing innovation: integrating technological, market and organizational change. West Sussex: John Wiley \& Sons, 2005.

VERGARA, S. C. Projetos e relatórios de pesquisa em administração. 2 ed. São Paulo: Atlas, 1998.

WBCSD - World Bussines Council for Sustainable Development. Disponível em: <www.wbcsd.org>. Acesso em: 10 julho 2015

YIN, R. K. Estudo de Caso: Planejamento e Métodos. $2^{\circ}$ ed. Porto Alegre: Bookman, 2001.

ZANELLA, L. C. H. Metodologia de estudo e de pesquisa em administração. Florianópolis: Departamento de Ciências da Administração/ UFSC; [Brasília]: CAPES :UAB, 2009

ZAWISLAK, P.A. A relação entre conhecimento e desenvolvimento: a essência do progresso técnico. Análise: Porto Alegre, PUC, v. 6, n. 1, p. 125-149, 1995. 